\title{
Characterization of microsatellite loci in Formica lugubris $B$ and their variability in other ant species
}

\author{
M. CHAPUISAT \\ Musée de Zoologie, PO Box 448, 1000 Lausanne 17 and, Institut de Zoologie et d'Ecologie animale, 1015 Lausanne, Switzerland
}

Fine-scale studies of the genetic structure of social insects, at both the nest and the local population levels, are important to evaluate the role of kin selection in the evolution and maintenance of social behaviour (Hamilton 1964a;b). Highly polymorphic genetic markers such as microsatellites will be useful to measure important parameters of insect societies, including genetic relatedness between nestmates, effective queen number, number of matings per queen, partitioning of reproduction among queens or males, and worker reproduction (e.g. Pamilo \& Crozier 1982; Pamilo 1991; Evans 1993; Hamaguchi \& Itô 1993; Queller et al. 1993; Keller \& Reeve 1994; Gertsch et al. 1995). Microsatellites will also permit detailed analyses of the local population structure, thus providing insight into mating system and gene flow (e.g. Bruford \& Wayne 1993; Slatkin 1995).

The red wood ant Formica lugubris type B (Pamilo et al. 1992) is abundant in the Swiss Jura mountains. At one site, over thousand mounds are connected by trails to form a supercolony, and hundreds of queens reproduce in each nest (Cherix 1980). A high number of reproductive individuals sharing the same nest tends to decrease the genetic relatedness between nestmate workers. Such an organization is difficult to explain by kin selection theory (Hamilton 1964b, 1972; Nonacs 1988; Keller 1995).

In this paper the cloning and characterization of five microsatellite loci from Formica lugubris type B are described, and results are presented of cross-species amplification in 11 ant species.

A partial genomic library was constructed from ant genomic DNA digested with Sau3 A and selected for fragments between 300 and $500 \mathrm{bp}$. The library contained 2400 recombinant clones in a pBS vector and was screened with a mixture of $(\mathrm{TC})_{10}$ and $(\mathrm{TG})_{10}$ oligonucleotide probes labelled with the DIG system of Boehringer (Estoup et al. 1993). The presence of microsatellites was further con-

Keywords: microsatellites, single-locus DNA markers, ants, Formica, Formicidae

Received 8 January 1996; revision accepted 28 March 1996

Correspondence: Tel.: + 41-21-312-83-36 or + 41-21-692-41-64; Fax: + 41-21-323-68-40. E-mail: Michel.Chapuisat@izea.unil.ch firmed by Southern blotting. Twenty-one positive clones were isolated and 17 sequenced, resulting in $10 \mathrm{TC} / \mathrm{AG}$ and seven TG/AC microsatellites. Primers were designed for eight loci consisting of seven to 19 uninterrupted repetitions of dinucleotide motifs (Table 1).

The PCR amplifications were carried out in $10 \mu \mathrm{L}$ of reaction mixture containing $1.5 \mathrm{mM} \mathrm{MgCl}_{2}, 10 \mathrm{~mm}$ Tris$\mathrm{HCl}, 50 \mathrm{mM} \mathrm{KCl}, 75 \mu \mathrm{M} \mathrm{dCTP}, \mathrm{dGTP}$ and dTTP, $6 \mu \mathrm{M}$ $\mathrm{dATP}, 0.2 \mu \mathrm{g} / \mu \mathrm{l}$ BSA, $0.5 \mu \mathrm{M}$ of each primer, $1 \mu \mathrm{L}$ (about $10 \mathrm{ng}$ ) of template DNA extracted with phenol/chloroform, $0.05 \mu \mathrm{L}$ of ${ }^{35 S}$-dATP or $0.02 \mu \mathrm{L}$ of ${ }^{33} \mathrm{P}-\mathrm{dATP}$, and 0.5 $\mathrm{U}$ of Taq polymerase (Perkin-Elmer). After an initial 3-min denaturation step at $95^{\circ} \mathrm{C}$, the PCR consisted of 35 cycles, with $1 \mathrm{~min}$ at $95^{\circ} \mathrm{C}, 1 \mathrm{~min}$ at $55^{\circ} \mathrm{C}$ and $1 \mathrm{~min}$ at $72{ }^{\circ} \mathrm{C}$, followed by a final elongation step of $10 \mathrm{~min}$ at $72{ }^{\circ} \mathrm{C}$ (PerkinElmer and Biometra thermal cyclers). PCR products were analysed on standard sequencing gels (6\% acryl-bisacrylamide, $8 \mathrm{M}$ urea).

Four loci were polymorphic, one was monomorphic and three gave no or unscorable PCR product in Formica lugubris $B$. Each polymorphic locus had between four and 12 alleles in the large, but geographically restricted, sample analysed. The expected heterozygosity based on allele frequencies and assuming that the population is at Hardy-Weinberg equilibrium ranged from 0.21 to 0.85 (Table 1).

Cross-species amplification with primers of the five loci was tested in 11 ant species. Two belong to other subfamilies (Dolichoderinae, Myrmicinae), one to the same subfamily (Formicinae) but to a different genus (Camponotus), and eight to the same genus as the source species (Formica) (Table 2).

In the most distantly related species (Linepithema humilis and Leptothorax nylanderi), no detectable amplification product was found at four markers, and a single, shorter fragment was detected at one locus. Similar results were obtained in Camponotus rufipes, except that one more marker produced a single, shorter fragment. These data suggest that flanking regions of the microsatellites are often not sufficiently conserved to permit amplification across different ant genera. When the amplification was possible, the repeated sequence seemed to be missing, resulting in a shorter, monomorphic fragment. 
Table 1 Microsatellite loci from Formica lugubris type B

\begin{tabular}{|c|c|c|c|c|c|c|}
\hline Locus & Core repeat* & $\begin{array}{l}\text { Size* } \\
\text { (bp) }\end{array}$ & $\begin{array}{l}\mathrm{Nb} \text { of } \\
\text { alleles }^{+}\end{array}$ & $\begin{array}{l}\text { Freq. of most } \\
\text { common allele }^{+}\end{array}$ & $H_{\mathrm{e}}^{+}$ & Primers $\left(5^{\prime}-3^{\prime}\right)$ \\
\hline FL12 & $(\mathrm{TC} / \mathrm{AG})_{12}$ & 112 & 5 & 0.25 & 0.78 & $\begin{array}{l}\text { CGAATCGTGATGGTGAGC } \\
\text { CATGTCTTCGATAGGAATACCG }\end{array}$ \\
\hline FL20 & $(\mathrm{TC} / \mathrm{AG})_{17}$ & 118 & 12 & 0.18 & 0.85 & $\begin{array}{l}\text { TTAGCAAAACGTTTTCATTGC } \\
\text { TGTCCGACATAATCAATAGCG }\end{array}$ \\
\hline FL21 & $(\mathrm{TC} / \mathrm{AG})_{16}$ & 257 & 4 & 0.88 & 0.21 & $\begin{array}{l}\text { GCCTGTCTCCTCTTCCGG } \\
\text { CATTGGTACCGTTCAACGATG }\end{array}$ \\
\hline FL29 & $(\mathrm{TC} / \mathrm{AG})_{12}$ & 184 & 4 & 0.37 & 0.72 & $\begin{array}{l}\text { ATTGAGGAAGGCGGTGTTAC } \\
\text { CTTTAACGTATACCGTGCGG }\end{array}$ \\
\hline FL43 & $(\mathrm{TG} / \mathrm{AC})_{7}$ & 168 & 1 & 1.0 & 0.0 & $\begin{array}{l}\text { CGGAGGTGGTGAGACAAGC } \\
\text { AAAATAAGCAAAAGACTGCGTTC }\end{array}$ \\
\hline
\end{tabular}

* Sequenced allele + From a sample of 264 individuals from 30 nests (FL12 and FL21), 226 individuals from 30 nests (FL 20 and FL29) and 5 individuals from 5 nests (FL43). All nests were located in a single, continuous population.

$H_{\mathrm{e}}$ expected heterozygosity

\begin{tabular}{|c|c|c|c|c|c|}
\hline $\begin{array}{l}\text { Subfamily } \\
\text { Species }\end{array}$ & FL12 & FL2O & FL21 & FL29 & FL43 \\
\hline \multicolumn{6}{|l|}{ Dolichoderinae } \\
\hline $\begin{array}{l}\text { Linepithema humilis } \\
\text { Myrmicinae }\end{array}$ & $0(3)$ & $1(3)$ & $0(3)$ & $0(3)$ & $0(3)$ \\
\hline $\begin{array}{l}\text { Leptothorax nylanderi } \\
\text { Formicinae }\end{array}$ & $0(3)$ & $1(3)$ & $0(3)$ & $0(3)$ & $0(3)$ \\
\hline Camponotus rufipes & $0(3)$ & $1(3)$ & $0(3)$ & $1(3)$ & $0(3)$ \\
\hline Formica cinerea & $3(9)$ & $4(9)$ & $5(8)$ & $2(9)$ & $1(3)$ \\
\hline F. exsecta* & $1(5)$ & $2(1200)$ & $25(1200)$ & $1(5)$ & $1(5)$ \\
\hline F. uralensis & $2(3)$ & $4(3)$ & $3(3)$ & $6(3)$ & $1(3)$ \\
\hline F. truncorum & $2(5)$ & $4(5)$ & $6(5)$ & $2(5)$ & $1(5)$ \\
\hline F. rufa & $4(8)$ & $3(7)$ & $5(8)$ & $2(8)$ & $1(8)$ \\
\hline F. aquiloniat & $1(22)$ & $5(8)$ & $4(22)$ & $4(22)$ & $1(22)$ \\
\hline F. polyctena (Finland) $†$ & $1(8)$ & $2(2)$ & $3(8)$ & $3(8)$ & $1(8)$ \\
\hline F. polyctena (Switzerland) & $2(3)$ & $3(3)$ & $2(3)$ & $3(3)$ & $1(3)$ \\
\hline F. lugubris type A & $5(32)$ & $6(32)$ & $4(32)$ & $6(32)$ & $1(3)$ \\
\hline F. lugubris type B & $5(264)$ & $12(226)$ & $4(264)$ & $4(226)$ & $1(5)$ \\
\hline
\end{tabular}

Table 2 Number of alleles found in cross-species amplification with Formica lugubris $B$ primers. $0=$ no scorable amplification product.

Number of individuals analysed is given in parentheses

* L. Sundström, M. Chapuisat \& L. Keller, unpublished data. † P. Gertsch, unpublished data.

Microsatellites are thought to be in rapidly evolving noncoding regions, and cross-species amplification is generally restricted to closely related species (Queller et al. 1993). However, some microsatellites were conserved across 11 cetacean species from different families (Schlötterer et al. 1992), or even across seven species of marine and freshwater turtles from three families (FitzSimmons et al. 1995). The low level of conservation of microsatellites between different genera of ants probably reflects the ancient separation of these taxa. Subfamilies diverged about 65 millions years ago and the modern genera were already present in early Oligocene amber fossils (Hölldobler \& Wilson 1990).

In contrast, all five loci were always amplified in the eight Formica species tested (Formica lugubris type A, F. polyctena, F. aquilonia, F. rufa, F. truncorum, F. uralensis, F. exsecta and $F$. cinerea). The four loci which were polymorphic in F. lugubris B were also generally polymorphic in the other Formica species. Comparison across species is difficult because the number of individuals analysed in each species is unequal, and is small in some cases. Nevertheless, the level of polymorphism seems to vary from one species to another. In some species, the number of alleles is greater than in F. lugubris B, whereas it is not in some other species (see for example locus FL21 in F. exsecta, aquilonia and lugubris B).

Estoup et al. (1995) also found a high level of conservation of microsatellites across five bumblebee species (genus Bombus), with occasionally very different levels of variability between species. The high level of conservation 
of microsatellites among the nine Formica species is somewhat surprising, when compared with the low conservation between ant genera. It may indicate a relatively recent common ancestry for these Formica species.

The genus Formica exhibits tremendous intra- and interspecific variations in social and genetic structure, from species with single queen per nest to species in which nests contain more than a thousand queens (Rosengren $e t$ al. 1993). The microsatellites described here will be useful to analyse the genetic structure of these ants at both the intranest and the population levels.

\section{Acknowledgements}

I thank Arnaud Estoup, Laurence Favre and Grigorios Krey for useful technical advice, Laurent Keller, Manuel Ruedi and Jean-Luc Jannink for comments on the manuscript, Daniel Cherix for constant support, and Peter Vogel for providing the lab facilities of his Institute. Lotta Sundström and Pia Gertsch provided part of the crossspecies amplification data. This work was supported by the Fondation du 450e, University of Lausanne, and by the Swiss National Science Foundation (grants no. 31-36907.93 and 3100-040828.94)

\section{References}

Bruford M, Wayne R (1993) Microsatellites and their application to population genetic studies. Current Opinion in Genetics and Development, 3, 939-943.

Cherix D (1980) Note préliminaire sur la structure, la phénologie et le régime alimentaire d'une super-colonie de Formica lugubris Zett. Insectes Sociaux, 27, 226-236.

Estoup A, Solignac M, Cornuet J-M (1993) Characterization of (GT) $n$ and (CT) $n$ microsatellites in two insect species: Apis mellifera and Bombus terrestris. Nucleic Acids Research, 21, 1427-1431.

Estoup A, Scholl A, Pouvreau A, Solignac M (1995) Monoandry and polyandry in bumble bees (Hymenoptera; Bombinae) as evidenced by highly variable microsatellites. Molecular Ecology, 4, 89-93.

Evans JD (1993) Parentage analyses in ant colonies using simple sequence repeat loci. Molecular Ecology, 2, 393-397.
FitzSimmons NN, Moritz C, Moore SS (1995) Conservation and dynamics of microsatellite loci over 300 million years of marine turtle evolution. Molecular Biology and Evolution, 12, 432-440.

Gertsch P, Pamilo P, Varvio S-L (1995) Microsatellites reveal high genetic diversity within colonies of Camponotus ants. Molecular Ecology, 4, 257-260.

Hamaguchi K, Itô Y (1993) GT dinucleotide repeat polymorphism in a polygynous ant, Leptothorax spinosior and their use for measurement of relatedness. Naturwissenschaften, 80, 179-181.

Hamilton WD (1964a) The genetical evolution of social behaviour. I. Journal of Theoretical Biology, 7, 1-16.

Hamilton WD (1964b) The genetical evolution of social behaviour. II. Journal of Theoretical Biology, 7, 17-52.

Hamilton WD (1972) Altruism and related phenomena, mainly in social insects. Annual Review of Ecology and Systematic, 3, 193-232.

Hölldobler B, Wilson EO (1990) The Ants. Springer-Verlag, Berlin Heidelberg, $732 \mathrm{pp}$.

Keller L (1995) Social life: the paradox of multiple-queen colonies. Trends in Ecology and Evolution, 10, 355-360.

Keller L, Reeve HK (1994) Partitioning of reproduction in animal societies. Trends in Ecology and Evolution, 9, 98-102.

Nonacs P (1988) Queen number in colonies of social Hymenoptera as a kin-selected adaptation. Evolution, 42, 566-580.

Pamilo P (1991) Evolution of colony characteristics in social insects. II. Number of reproductive individuals. The American Naturalist, 138, 412-433.

Pamilo, P, Crozier, RH (1982) Measuring genetic relatedness in natural populations: Methodology. Theoretical Population Biology, 21, 171-193.

Pamilo P, Chautems D, Cherix D (1992) Genetic differentiation of disjunct populations of the ants Formica aquilonia and Formica lugubris in Europe. Insectes Sociaux, 39, 15-29.

Queller DC, Strassmann JE, Hughes CR (1993) Microsatellites and kinship. Trends in Ecology and Evolution, 8, 285-288.

Rosengren R, Sundström L, Fortelius W (1993) Monogyny and polygyny in Formica ants: the result of alternative dispersal tactics? In: Queen Number and Sociality in Insects (ed. Keller L), pp. 308-333. Oxford University Press, Oxford.

Schlötterer C, Amos B, Tautz D (1991) Conservation of polymorphic simple sequence loci in cetacean species. Nature, 354, 63-65.

Slatkin M (1995) A measure of population subdivision based on microsatellite allele frequencies. Genetics, 139, 457-462. 


\section{Erratum}

Bérubé M, Palsbøll P. (1996) Identification of sex in Cetaceans by multiplexing with three ZFX and ZFY specific primers. Molecular Ecology 5, 283-287.

There was an error in Figure 1 of this paper. The length of the fragments are incorrectly labelled on the figure.

The correct lengths are as follows:

Fig. 1A. $383 \mathrm{bp}$ and $227 \mathrm{bp}$ instead of $425 \mathrm{bp}$ and $269 \mathrm{bp}$ (primers for odontocetes)

Fig. 1B. $245 \mathrm{bp}$ and $212 \mathrm{bp}$ instead of $328 \mathrm{bp}$ and $254 \mathrm{bp}$ (primers for mysticetes)

This error consequently led to an error on p. 287, first columm last sentence of the first paragraph. This sentence should now read:

Hence, for each cycle, twice as many copies are synthesized of $245 \mathrm{bp}$ (one from the ZFY exon and one from ZFX exon) as of the $212 \mathrm{bp}$ ZFY-specific fragment.

Also, in the legend of Figure 2, the following should be added:

The underlined oligonucleotide primers were used for amplification and sequencing.

Finally, the author box was omitted from the original manuscript and is now reproduced below.

Martine Bérubé is a PhD candidate at McGill University. The main focus of Martine Bérubé's project is the evolution and population structure of the North Atlantic Fin whale. Martine Bérubé has been working at the Copenhagen University as an exchange student. Per Palsbøll is post doc. at the University of Copenhagen directing the whale group. The whale group focus on population genetics and evolutionary aspects of North Atlantic cetaceans by use of molecular techniques. 